anomalies, and a typical number of other phenotypes, including occurrence of cardiac fibroma. The syndrome is caused by microdeletion of the long arm of chromosome 9, in the region q22.3-q31 which includes the $\mathrm{PTCH}$ tumor suppressor gene. The diagnosis is made clinically, through large and small criteria that include the already mentioned clinical characteristics.

Case Report We will present the case of a 5 - year - old girl diagnosed with Gorlin - Goltz syndrome with the presence of fibroma in the left ventricular wall. The patient has an uneven psychomotor development and shows atypicalities in the field of socio-emotional functioning. Phenotypically, we find increased neurocranium, rough facial features, divergent strabismus, and a wider nasal root. The girl was initially hospitalized for the clinical presentation of heart failure: she was clinically tachydyspnoic, with audible crepitations in the lungs, enlarged liver, and pretibial edema. Echocardiographically, it was diagnosed with dilated cardiomyopathy, with an ejection fraction of $25 \%$, while the formation of an unclear etiology was seen in the left ventricle. The patient was treated with anticongestive therapy with low molecular weight heparin and further treatment was performed. MRI of the heart showed a formation that according to radiological criteria corresponds to a large fibroma. Due to the opinion that dilated cardiomyopathy and fibroma with phenotypic characteristics could be parts of systemic disease, molecular karyotyping was performed which found microdeletion of the long arm of chromosome 9 in the q22.3 region, which includes the PTCH gene that regulates cell growth and functions as a tumor suppressor gene. Haploinsufficiency of this gene has been described as Gorlin - Goltz syndrome, which is characterized by phenotypic traits such as those found in our patient. Among patients with Gorlin-Goltz syndrome, 10\% develop cardiac fibroma with the most common localization in the left ventricular cavity. Symptoms of cardiac fibroma depend on the size of the tumor, the involvement of the conduction system, and the possible existence of intracavitary obstruction. The patient we present has an extensive tumor located intramurally in the anterolateral wall of the left ventricle, measuring $5.8 \times 4.8 \mathrm{~cm}$. Measured values of cardiac pressures obtained by invasive cardiac treatment indicate impaired systolic and diastolic heart function and increased pulmonary pressure, as a result of dilated cardiomyopathy with clinical signs of heart failure.

Discussion The presence of dilated cardiomyopathy with markedly impaired systolic function may be secondary to the tumor or as primary disease, that is why genetic processing of cardiomyopathy is ongoing. Cardiac fibroma can be treated by surgical resection, but in a situation of severely impaired systolic function, transplantation treatment is more likely, with the risk of immuosuppression in a patient with a tumor suppressor gene disorder.

\section{FIRST CROATIAN GUIDELINES FOR DIAGNOSIS AND TREATMENT OF ARTERIAL HYPERTENSION IN CHILDREN AND ADOLESCENTS}

Vesna Herceg-Čavrak*, Dalibor Šarić, Hrvoje Kniewald, Višnja Tokić Pivac, Martin Ćuk, Ivana Trutin, Đurð̌ica Košuljandić, Adela Arapović, Dejan Balažin, Vera Musil, Vesna Jureša, Bojan Jelaković, Nikolina Benco, Bernardica Valent Morić. Klinika za dječje bolesti Zagreb

10.1136/archdischild-2021-europaediatrics.191
Hypertension in children and adolescents is a growing public health problem. The risk of developing hypertension in children is higher than ever before due to adverse circumstances such as obesity, excessive salt and processed food intake, reduced physical activity and stress. Hypertension is transmitted from childhood, and especially adolescence, into adulthood and thus increases the risk for cardiovascular disease in adulthood. As information regarding pediatric hypertension has changed over the last few decades, we have developed the first Croatian guidelines for the diagnosis and treatment of hypertension in children and adolescents based on recent literature and guidelines of international societies adapted to our circumstances. Fourteen doctors from different centers - members of the pediatric hypertension working group from the Croatian Society of Hypertension - participated in the development of our guidelines. We tried to cover various aspects of pediatric hypertension - epidemiology, prevention, primary and secondary hypertension, diagnosis, vascular phenotype factors, athlete hypertension, neonatal hypertension, treatment of hypertension and hypertensive urgency and emergency. With these recommendations, we tried to make it easier for doctors to cope with the issue of pediatric hypertension, as well as offer practical instructions on how to deal with such patients. These are all reasons why we believe that the guidelines, written by members of the Croatian Society of Pediatric Cardiology and Rheumatology, the Croatian Society of Pediatric Nephrology, the Croatian Society of School and University Medicine and the Croatian Society of Hypertension, will be useful in prevention, active search for hypertension in children and its treatment. The guidelines can be found on the website of the Croatian Society for Hypertension https://hdh.emed.hr/ upload/hdh_smjernica/dokument_1581600283.pdf

\section{ALAGILLE SYNDROME IN INFANT WITH FALLOT TETRALOGY}

${ }^{1}$ Stjepan Herceg*, 1,2Daniel Dilber, 1,2Dalibor Šarić, 1,2Dorotea Bartoniček, 1,2 Marina Mihalec, ${ }^{1,3}$ Sanda Huljev Frković, ${ }^{1,4}$ Dražen Belina, ${ }^{4}$ Željko Đurić, ${ }^{4}$ Mislav Planinc. ${ }^{1}$ School of Medicine, University of Zagreb; ${ }^{2}$ Department of Cardiology, Clinic of Pediatrics, University Hospital Center Zagreb; ${ }^{3}$ Department of Medical Genetics and Metabolic Diseases, Department of Pediatrics, University Hospital Center Zagreb; ${ }^{4}$ Department of Pediatric Cardiac Surgery, University Hospital Center Zagreb

\subsection{6/archdischild-2021-europaediatrics. 192}

Introduction Alagille syndrome is an autosomal dominant disorder that primarily affects the liver and heart. The genetic basis for the development of the syndrome is a mutation in the JAG1 gene (in most cases) or the NOTCH2 receptor. The syndrome is clinically characterized by chronic cholestasis, congenital heart defect (most often pulmonary stenosis), abnormalities in the skeletal system ('butterfly' vertebrae), changes on the eyes (posterior embryotoxon) and characteristic phenotype. The prevalence of the syndrome is estimated at 1:30 000 live births.

Case Report We will present a male infant aged 10 months with a diagnosis of Alagille syndrome. The boy was born from his mother's first, regularly controlled pregnancy. The boy was vital at birth with mild neonatal jaundice. On the third day of life, a systolic murmur was observed over the precordium, louder along the left edge of the sternum, and a diagnosis of tetralogy of Fallot was made by echocardiography. During the next examination, at the age of one month, the classic form of tetralogy of Fallot was verified by ultrasound 
with infundibular and valvular stenosis of the pulmonary artery with ultrasound pressure gradient over pulmonary stenosis of about $50 \mathrm{mmHg}$. The infant, then at the age of 4 months, underwent invasive cardiac procedure during the next hospitalization, showing pulmonary branches: the initial part of the right branch was $5 \mathrm{~mm}$, followed by a fully hypoplastic right branch $(3 \mathrm{~mm})$ with middle segment stenosis up to 2 $\mathrm{mm}$; the left branch is even more hypoplastic, entirely 2.2 $\mathrm{mm}$ with $2 \mathrm{~mm}$ segments. According to the finding, surgery was performed to establish an aortic-pulmonary anastomosis in the form of an mBT (modified Blalock Taussig) compound. In addition to cardiac processing, elevated levels of liver transaminases, primarily GGT enzymes, were observed in the findings. Due to the justified suspicion of Alagille's syndrome (tetralogy of Fallot with elevated liver transaminases), an X-ray of the spine was performed, where the fusion of the bodies of the Th6 and Th8 vertebrae was found, the so-called 'butterfly' vertebrae. Among other things, an ophthalmological examination was performed where the posterior embryotoxon of both eyes was observed. Complete processing met the higher diagnostic criteria for Alagille's syndrome, and therefore genetic analysis was requested, which confirmed the heterozygous variant in the JAG1 gene and diagnosed Alagille's syndrome. During the last hospitalization, cardiac catheterization was performed, which still showed hypoplastic pulmonary branches with a narrow mBT joint.

Discussion/Conclusion Although pulmonary stenosis is the most common heart defect within Alagille syndrome, tetralogy of Fallot with hypoplasia of the pulmonary branches may also be one of the clinical manifestations. Since the pulmonary branches are still hypoplastic in our patient after aorthopulmonary anastomosis, in the idea of better pulmonary blood supply, dilatation of the pulmonary valve with a balloon was performed for better anterograde flow until a decision on further treatment modality.

\section{Paediatric Clinical Pharmacology and Toxicology}

\section{POPPY SEED DEFENCE}

Maja Vinkovic*, Nevena Krnic, Anita Spehar Uroic, Katja Dumic Kubat, Miroslav Weiss. Department of Pediatrics, University Hospital Center Zagreb

\subsection{6/archdischild-2021-europaediatrics. 193}

Acute loss of consiousness in an adolescent prompts detailed evaluation, including toxicology analysis. In case of a positive opiate test, it is of outmost importance to confirm or exclude drug abuse, which can have important legislative consequences.

We present a 17-years-old boy who was admitted due to acute loss of consiousness. After getting up, he felt dizzy and then fainted, followed by myoclonic jerks. He recovered spontaneously. His previous history, physical and neurological examination were unremarkable. Initial laboratory evaluation, ECG and EEG were normal but urine toxicology screening tested positive for opiates $(4565 \mathrm{nmol} / \mathrm{l}=1305 \mathrm{ng} / \mathrm{ml}=1.3$ $\mathrm{ug} / \mathrm{ml})$. He denied previous use of any medications or illicted drugs. However, he reported eating large quanities of poppy seed cake in the morning and during the previous day. The following day the opiate screen was negative. According to the data in the literature, oral intake of cakes containing commercially available poppy seeds can produce urine morphine concentrations ranging from

1 to $10 \mathrm{ug} / \mathrm{ml}$ and morphine can be detected in the urine for up to 48 hours following ingestion. Opiate concentrations produced by poppy seeds ingestion depend on the origin of poppy seeds, lot, and baking technique. To confirm the possibility of false positive test, a volunteer at the Department eat the same poppy seed cake followed by urine toxicology analysis which tested opiate positive. The patient was discharged from the hospital with diagnosis of vasovagal syncope.

A detailed patient-oriented history is essential in order to establish the correct diagnosis. The possibility of false-positive opiate drug tests after poppy food ingestion should always be considered. There are no data regarding 'safe' quantity of food containing poppy seeds that would not interfere with drug test. It is important to know the limitations of toxicology analysis in order to avoid unnecessary stigmatization of a patient and serious legal drawback.

\section{LATE-PRESENTING ACETAMINOPHEN SELF-POISONING}

Nikolina Benco Kordić*, Mila Lovrić, Arnes Rešić, Miro Bakula Clinical Hospital Sveti Duh. Children's Hospital Zagreb

\subsection{6/archdischild-2021-europaediatrics. 194}

We report a case of a 15-year-old adolescent girl who presented to the Intensive Care Unit (ICU) of Children's Hospital Zagreb 38 hours after having intentionally ingested 10 tablets od $1000 \mathrm{mg}$ acetaminophen and 7 tablets of $500 \mathrm{mg}$ acetaminophen (13.5 grams). Initially, she presented to the Emergency Department of General Hospital Virovitica, 36 hours after ingestion, main complaint was nausea, vomiting and abdominal pain. She was conscious with mild scleral icterus, euthermic, BP $97 / 63 \mathrm{mmHg}$, HR 73/min. Initial serum chemistry measured PT 0.27, AST $2138 \mathrm{U} / \mathrm{L}$, ALT $2069 \mathrm{U} / \mathrm{L}$, creatinine 75 umol/L. Vitamin K was administered and she was transferred to the ICU. Due to ingestion of toxic acetaminophen dose, $\mathrm{N}$ acetylcysteine (NAC) was initiated, starting with loading dose of 6.6 grams over 1 hour, then 2.2 grams over 4 hours, continued with maintenance dose of 4.4 grams over 16 hours, following the 21-hour NAC protocol. Blood tests were performed daily, including complete blood count, renal and liver functions, ammonia, prothrombin time and blood gas analysis. Results revealed elevated levels of transaminase, peak values AST 11567 U/L, AST 10681 U/L, LDH 9651 U/L, high ammonia values, peak value $158 \mathrm{umol} / \mathrm{L}$, and coagulopathy, peak INR value 4.04. Abdominal ultrasound reported diffusely enlarged hypoechoic liver, measuring $14 \mathrm{~cm}$ in the midclavicular line, with hypoechoic area, $3 \mathrm{~cm}$ in size, which may correspond with necrosis zone.

Parenteral rehydration, hepatic diet and psychological support were implemented during the hospitalization. Serum acetaminophen levels were measured daily. 36 hours after ingestion, level was $557 \mathrm{umol} / \mathrm{L}$.

Concentrations were detectable until the seventh day after ingestion, so NAC was discontinued after 6 days of treatment, when concentrations were undetectable and liver enzymes decreased. Psychiatric evaluation was conducted, she was characterised as a perfectionist, very ambitious, not previously known to have any psychiatric or organic health issues. The 